Cadena Durán, O., y Lozano Botache, J. (2013). El sentido de lo comunitario: tensiones entre el liberalismo y comunitarismo en territorios locales del Cauca, Colombia. Revista Lebret (5). Bucaramanga - Colombia: Universidad Santo Tomás, pp 71-86.

\title{
El sentido de lo comunitario: tensiones entre el liberalismo y comunitarismo en territorios locales del Cauca, Colombia*
}

\author{
The sense of community: tensions between Liberalism and \\ Communitarianism in local territories of Cauca, Colombia
}

Olga Lucía Cadena Durán

Jorge Prudencio Lozano Botache

\begin{abstract}
Resumen
El propósito de la investigación que sirvió de base a este artículo consistió en identificar aspectos que inciden sobre la historia ambiental de los procesos de solidaridad y de fortalecimiento de identidades locales y regionales en territorios rurales del suroccidente colombiano. La metodología se basó en el diseño y realización de talleres itinerantes de Diagnóstico Rural Participativo, registros etnográficos y entrevistas semiestructuradas. Entre los resultados se resalta cómo en el Departamento del Cauca las tensiones éticas y políticas entre el Liberalismo y el Comunitarismo, se convierten en temas centrales a la hora de definir el sentido de lo comunitario en campesinos, afrodescendientes e indígenas.
\end{abstract}

\section{Palabras clave}

Comunitarismo, Liberalismo, Buen Vivir Rural, Economías con Solidaridad.

\section{Códigos de Clasificación JEL: A2, P5}

\begin{abstract}
The purpose of the research was to identify the aspects influencing the environmental history of solidarity and strengthening processes of local and regional identities in rural areas in southwest Colombia. The methodology was based on the design and the carrying out of itinerant workshops of Participatory Rural Development, Ethnographic records and semistructured interviews. The results highlight the ethical and political tensions in the department of Cauca between liberalism and communitarianism which become central issues in the definition of the sense of community in rural, indigenous and Afro-descendant population.
\end{abstract}

\section{Keywords}

Communitarianism, Liberalism, Good Rural Living, Solidarity Economies.

* $\quad$ Este artículo se deriva del proyecto de investigación "Análisis del microcrédito y su impacto en los aspectos socioeconómicos en la ciudad del Popayán” cofinanciado por la Universidad del Cauca, la Universidad Santiago de Cali, la Fundación Mundo Mujer (FMM) y comunidades rurales del suroccidente colombiano, que participaron en los procesos. Ha sido un trabajo interdisciplinar entre estudiantes, docentes, comunidades campesinas en Totoró, Popayán, Timbío, El Tambo, Mercaderes y Bolívar; comunidades indígenas en Puracé, Sotará, Silvia, San Sebastián y en La Vega; comunidades afrodescendientes en Patía y Balboa y comunidades urbanas de estratos 0, 1 y 2 en Popayán, Departamento del Cauca, Colombia.

Los autores agradecen a las organizaciones comunitarias de base, a la Fundación para la comunicación Popular Funcop y a todo el equipo de trabajo de la Universidad del Cauca (estudiantes de Economía y docentes) y de la Universidad Santiago de Cali (estudiantes de Comunicación social y docentes), por la oportunidad de hacer posible este trabajo, de re-pensar el trabajo académico, el comunitario y por permitir acercar la Universidad a las comunidades urbanas y rurales en el suroccidente colombiano.

1 Estudiante de doctorado en Ciencias Ambientales, Universidad del Cauca, Colombia. Investigadora y Docente Asociada del Departamento de Ciencias Económicas, Universidad del Cauca, Colombia. Correo electrónico: olgacadena@unicauca.edu.co

2 Doctor en Ciencias de la Educación, Universidad del Cauca, Colombia. Director del Departamento de Comunicación de la Universidad Santiago de Cali, Colombia. Correo electrónico: jorgeprudenciol@yahoo.com 


\section{Introducción}

Esta reflexión parte de una investigación ${ }^{3}$ realizada sobre prácticas comunitaristas entre campesinos, afrodescendientes e indígenas de diferentes lugares del Departamento del Cauca desde enero de 2010 hasta noviembre de 2011. Las vivencias compartidas con las comunidades aportaron elementos para realizar una comparación entre el ejercicio práctico del Liberalismo y del Comunitarismo en sus organizaciones y su incidencia sobre la historia ambiental de sus territorios.

En los municipios de Popayán, El Tambo, Timbío, Patía, Bolívar, Balboa, Mercaderes, Sotará, San Sebastián y La Vega, las comunidades urbanas, indígenas, campesinas y afrodescendientes que allí habitan, han realizado siempre prácticas comunitarias de resistencia y autonomía frente a las políticas liberales imperantes, cuyos efectos ambientales han sido desastrosos. Desde aquellas experiencias ha sido posible dar cuenta de las tensiones éticas y políticas entre el liberalismo y el comunitarismo que se convierten en temas centrales a la hora de concebir el sentido de lo comunitario y su importancia para atenuar el deterioro ambiental. En la búsqueda de una opción que aporte elementos en el análisis frente a la disyuntiva abierta entre economía mercantilista y ecología preservacionista se plantea la urgencia de construir una propuesta económica y comunitarista.

Dentro de ese marco, esta investigación se orientó hacia la identificación de procesos con solidaridad y el fortalecimiento de la identidad local y regional en los territorios, reconociendo su manera particular de vivir y sus economías propias ( y dentro de ellas las formas de calcular los "costos" de producción e ingresos efectuando prácticas de autoconsumo como los cambios de mano, las mingas y los intercambios recíprocos), reconstruyendo memoria social y ambiental y reconociendo que la institucionalidad cumple también varios roles específicos en estos procesos.

Estas exploraciones permitieron caracterizar a las comunidades con propuestas alternativas de buen vivir, examinar las condiciones básicas del bien estar alternativo local en lo referente a la construcción del sentido de lo público, al fortalecimiento del capital social, de redes sociales, del talento humano y de alianzas institucionales; interpretar las dinámicas integrales del bien estar alternativo local, en lo relacionado con las prácticas de convivencia, de economías con solidaridad, de gobernabilidad y de sostenibilidad para la vida; diseñar e implementar habilidades que apoyen las dinámicas de generación, adopción, transferencia e intercambio de saberes interdisciplinarios locales; potenciar la identidad cultural y organizativa comunitaria

3 Esta investigación se realizó en el marco de la línea de profundización en la Universidad del Cauca denominada "Sociedades y Economías rurales". Ha sido un trabajo interdisciplinar entre estudiantes, docentes, comunidades campesinas en Timbío, El Tambo, Mercaderes y Bolívar; comunidades indígenas en San Sebastián y en La Vega; comunidades afrodescendientes en Patía y Balboa; y con comunidades urbanas de estratos 0,1 y 2 en Popayán; todas viven en el departamento del Cauca. Los resultados parciales se sintetizaron en una ponencia presentada en la Universidad Javeriana, año 2011. 
de las comunidades mediante una capacitación en las técnicas de la narración audiovisual en cada una de las zonas.

La metodología se basó en el empleo de herramientas de Diagnóstico Rural Participativo (DRP) y en la Etnografía. Las comunidades educativas campesinas, indígenas y afrodescendientes fueron protagonistas activas de sus procesos y con base en la Hermenéutica de la Acción y en equipo, se realizó la sistematización y organización de la información en forma narrativa-audiovisual.

Así pues, en la caracterización de las comunidades con propuestas alternativas del buen vivir, se diseñaron y realizaron talleres itinerantes de DRP, registros etnográficos y entrevistas semiestructuradas, identificando actividades de generación, adopción y/o transferencia de conocimiento local, a partir de sus procesos. Para el análisis de efectos socioculturales, económico- ambientales y organizativos de estas propuestas, se aplicó e interpretó la matriz de necesidades y satisfactores de Max-Neef (1986), a través de talleres participativos y de registro etnográfico. Con el fin de examinar las condiciones básicas de bienestar y las dinámicas integrales del mismo, se realizaron talleres participativos con las comunidades a los que se le agregaron registros etnográficos. Con el propósito de potenciar la identidad cultural y organizativa comunitaria, se iniciaron procesos de capacitación en técnicas de la narración audiovisual a miembros de cada una de las Comunidades participantes.

\section{Entre el paradigma liberal y el paradigma comunitarista: algunos valores $y$ tensiones}

En la complejidad de esta época, lo comunitario bien puede ser analizado desde la dinámica relación que hay entre varios paradigmas éticos que coexisten en las diferentes sociedades. No obstante, en este escrito se hace énfasis en dos de ellos: el paradigma liberal y el paradigma comunitarista propiamente dicho.

Se asume al liberalismo, por una parte, desde la concepción clásica que se forjó en los albores de la modernidad (según algunos autores en el siglo XV y según otros en el XVIII) y que se manifiesta principalmente en tres aspectos: el filosófico, el político y el económico. A nivel filosófico se destaca la idea de autonomía individual y especialmente de libre-pensamiento, cuyos desarrollos conceptuales se encuentran en la obra de Emannuel Kant (2000) y pasa posteriormente por tendencias voluntaristas y existencialistas; a nivel político se destaca la idea de contractualismo social en todas sus versiones y planteamientos sobre el pluralismo, el estado, los poderes públicos y la democracia, desde autores como Lock y Toqueville. A nivel económico se destaca la idea de libre concurrencia presente en la economía clásica desde Adam Smith y David Ricardo

Por otra parte, se entiende que el liberalismo se ha perfilado éticamente desde la época clásica hasta nuestros días en diferentes matices que devienen en 
liberalismo social o en neoliberalismo. El primero, manteniendo la preponderancia del librepensamiento, señala la importancia de garantizar condiciones mínimas de existencia material a todos los individuos para que pueda existir un contractualismo democrático, como ocurre dentro del llamado estado de bienestar y desde teóricos como John Rawls (1971); el segundo le da mayor relevancia a la capacidad gestionadora de empresas por parte de los individuos hasta incluso considerar que el estado es un obstáculo para la libertad, como ocurre en las prácticas económicas del llamado capitalismo salvaje y desde filósofos como Robert Nozick.

En contraste, el comunitarismo como comportamiento colectivo y en cuanto elaboración filosófica surge como reacción frente al liberalismo. En este texto interesa diferenciar, por una parte, al comunitarismo que reclama a la pureza étnica, la supremacía intolerante de la tradición propia frente a otras y la prevalencia absoluta de los intereses del grupo sobre los del individuo, como ocurre con algunas comunidades religiosas o políticas denominadas fundamentalistas. Por otra parte, es factible identificar distintos matices de comunitarismo en los que se valora a la tradición dentro de una tensión entre permanencia y transformación, se reconoce como una riqueza a la variedad étnica de la humanidad, se promueve la necesidad de convivir e interactuar con otras culturas, en el seno de la multiculturalidad y el dinamismo de la autonomía comunitaria para el despliegue de la historia de toda la humanidad como ocurre en la mayoría de las comunidades ancestrales de todos los continentes o desde filósofos como Taylor y McIntyre (1976) .

Es importante considerar que una comunidad no es sólo un grupo de personas sino, sobre todo, un conjunto de sentidos y vivencias compartidas por tales personas (Quijano, 2010), bien sea en un mismo territorio o a través del ciberespacio. Si, como ya se afirmó, para el liberalismo la libertad es el valor más importante, para el comunitarismo lo es la felicidad, sin que ello signifique que al liberalismo no le interese la felicidad entendida en términos del individuo o que al comunitarismo para el que la felicidad es una realización ligada a la trayectoria trazada por la vida colectiva- no le interese la libertad, entendida en términos de la intersubjetividad y la autonomía comunitaria. Para el paradigma comunitarista, de estirpe teórica también europea pero vivencialmente palpable en este medio con mucha autenticidad, la felicidad puede ser rastreada como concepto desde la Filosofía Aristotélica, principalmente en la "Ética a Nicómaco" (2005) $)^{4}$ pero también en la concepción de la Tragedia que subyace a su obra "La Poética" y en las concepciones que expone en "La República" (2005).

4 En su "Ética a Nicómaco", Aristóteles indica que la felicidad consiste en realizar algún tipo de actividad que permita alcanzar la excelencia del carácter y las facultades intelectivas. Esto significa llevar una vida virtuosa y noble, es decir, que beneficie a la polis, que para el caso puede adecuarse a una noción de comunidad. La felicidad que le corresponde al hombre es la que le sobreviene cuando realiza la actividad que le es más propia y cuando la realiza de un modo perfecto. Aristóteles también acepta que para ser feliz es necesaria una cantidad moderada de bienes exteriores y afectos humanos que permitan alcanzar la felicidad entendida de esta manera. 
El Liberalismo mismo empezó como una transformación de las tradiciones y tuvo que enfrentarse con las resistencias al cambio lideradas, por ejemplo, por los románticos, defensores del vínculo del individuo con el villorrio y el paisaje (de donde proviene la palabra país). En Europa finalmente triunfó el Liberalismo, no obstante, en el resto del mundo "la discusión" ha tenido otros ribetes: en el Continente Americano, por ejemplo, se ha llegado a hablar de las "culturas híbridas" (García Canclini, 1990) para hacer referencia a la mezcla entre las transformaciones que fueron forjadas por el Liberalismo con las tradiciones indígenas que perviven y que a su vez transforman al legado liberal.

Sin embargo, en este continente también perviven comunidades indígenas campesinas y afrodescendientes, dentro de las cuales la tensión es inversa a la que le ocurrió al Liberalismo en sus albores: mientras que el Liberalismo fue emergente y luchó para imponerse, el comunitarismo indígena, el comunitarismo campesino y el comunitarismo afrodescendiente existen, y luchan para no desaparecer.

Los individuos integrantes de algunas comunidades rurales tal como ocurre, por ejemplo, en el actual Departamento del Cauca, viven cada uno dentro de sí una permanente tensión interna: dentro de su comunidad son, como ellos suelen decir: "Comuneros", a veces integrantes del Gobierno Indígena llamado Cabildo -Pueblos indígenas kokonuko, yanaconas, ambalueños, totoroes, guambianos, paeces-, o de la Organización de la Junta de Acción Comunal -los campesinos de El Tambo-, o Veredal -los campesinos de La Vega, de Bolívar, de Balboa-, o forman parte del "grupo étnico local" - los grupos afro de Puerto Tejada, Buenos Aires, Santander de Quilichao-, o de la "Comunidá" - comunidades afro de Pílamo en Guachené, de Caloto-, o del "Consejo Comunal" -en Patía, Balboa, Mercaderes-. Sin embargo, una vez salen de su comunidad y entran en interacción con la institucionalidad liberal que caracteriza a la ciudad (con vestigios del liberalismo clásico y mezclas tanto de liberalismo social como de neoliberalismo), los individuos pasan a ser formalmente ciudadanos sin autoridad más allá de la que puedan ejercer por medio de su capacidad adquisitiva, con más deberes que derechos.

\subsection{Hacia un buen vivir en los territorios: otras concepciones comunitaristas}

Las sociedades rurales caucanas han venido explorando e implementando diferentes estrategias socioculturales, económicas y ambientales en sus sistemas de producción, de organización y de convivencia para suplir sus necesidades humanas fundamentales ${ }^{5}$ mediante vivencias alternativas de tipo ambiental, cultural, organizativo, que resuelven necesidades axiológicas relacionadas con el ocio, la recreación, la libertad, la identidad, la protección, la participación, el entendimiento, el afecto, entre otras. Estas vivencias se caracterizan por basarse en un gran acervo

5 Según Manfred Max-Neef, las necesidades humanas fundamentales no se resuelven sólo con dinero, existen otros satisfactores diferentes a este, y está relacionados con lo que se menciona más adelante. 
sociocultural, organizativo y ambiental no monetario, que ha permitido mantener una calidad de vida y que representan un importante potencial para dignificar aún más la vida para todos y todas dentro de sus territorios.

Se trata de la aplicación de sistemas locales a través de siete perfiles alternativos de bien estar rural. El primero es el de la producción orgánica en huertas escolares y caseras ${ }^{6}$ para una alimentación y un consumo saludables con mínimo uso de insumos químicos con el fin de proteger al agua y el suelo; rescatando el conocimiento ancestral frente a lo ambiental y las semillas locales, valorando los roles con perspectiva de género en los diferentes ámbitos de interacción, realizando trueques, socializando vivencias organizativas y ambientales e incorporando los productos de estas prácticas al menú diario de las instituciones educativas y sus comunidades. El segundo perfil es el relacionado con el tiempo libre, la recreación y el deporte, mediante el cual se promueve la invención de objetos, rondas, juegos, participación en festivales deportivos, campamentos, trabajo manual, semilleros de creación, entre otras actividades?

El tercero, contribuye al fortalecimiento de la medicina tradicional y al buen manejo de la "medicina blanca" conservando botiquines con medicamentos de las tres culturas (campesina, indígena y afrodescendiente) para primeros auxilios, montando y sosteniendo un jardín botánico, recuperando y conservando especies de fauna y flora, respetando las perspectivas de vida y muerte de diversas religiones mediante diversos rituales, la sanación del cuerpo y del alma a través de consejos con la valoración de la espiritualidad y de la relación directa entre la naturaleza y el ser humano, quien forma parte de esta ${ }^{8}$. El cuarto aspecto, es el que trabaja los temas de la convivencia, la paz, los anti-valores, la relación ser humano-naturalezasociedad. En este perfil se analizan y promueven los deberes y los derechos humanos y de los grupos étnicos, el DIH, el buen trato, las reglas en los juegos, la cátedra de estudios afrocolombianos, la identificación de conflictos, el análisis y evaluación de soluciones locales, la legislación existente sobre comunidades, la concertación, entre otros ${ }^{9}$.

El quinto, hace referencia al estudio socio-histórico de las comunidades mestizas, las etnias, su hoy, su ayer y el posible porvenir, a través de danzas, teatro, artesanías, la valoración del conocimiento de los mayores: las bibliotecas vivas; el inventario de las habilidades y los cantos, entre la comunidad, entre otras actividades. En este aspecto se rescatan prácticas socioculturales con la naturaleza que contribuyen a una

\footnotetext{
Hace referencia a nutrición, bienestar, seguridad alimentaria y ambiente

Entre las que se incluyen el tiempo libre, la recreación y deporte.

Se refieren a labores de curandería de cuerpo, alma y espíritu.

En el sur del Departamento, en el municipio de Patía, quienes practican esto se han autodenominado Artesan@s de la paz.
} 
larga permanencia en sus territorios ${ }^{10}$. El sexto perfil se encarga de la conservación y restauración de los recursos naturales, identificando el estado actual del recurso hídrico, la flora, la fauna y la biodiversidad; la valoración del potencial turístico de la región, para buscar una generación de ingresos adicionales a las precarias labores convencionales de la zona; la reconstrucción de una memoria social ambiental, con el fin de tener una mayor conciencia sobre los impactos mutuos entre comunidad y naturaleza, entre otros ${ }^{11}$. A su vez, el séptimo es el que practica la combinación entre oralidad y literatura, crea escuelas de liderazgo, de poetas y poetizas, jeringonceros, escritores, filósofos; muestra la importancia de valorar la vida, la salud sexual y reproductiva, la prevención de sustancias psicoactivas, el amor, los estilos de vida saludables; la mendicidad, la dignidad, el desempeño en el trabajo; las relaciones sociales, las formas de vida y su disfrute, analiza textos y contextos, expresiones corporales, danzas, teatro, música, manejo de emociones, y habilidades para la vida ${ }^{12}$.

Cuando la misma gente construye la historia de estas interacciones hay más posibilidades de entender los umbrales de crecimiento, valorarlos, y apropiarlos de otra manera, concibiendo el fragmento del planeta habitado por las comunidades humanas específicas dentro de unas relaciones de pervivencia características de quien habita una "casa" (significado de la raíz etimológica "oikos" con la cual se conforman las palabras ecología y economía). Todas estas expresiones indican que muchas comunidades están de acuerdo con que hay nuevas concepciones frente al conocimiento y a las formas de vivir, la creación, la sabiduría ${ }^{13}$ y los procesos al servicio del bienestar de las comunidades, que son particulares para cada población, que se derivan de ellas mismas -las comunidades-, que exigen una mayor conciencia local frente a la evaluación de sus condiciones sociales, económicas, organizativas, culturales y ambientales, un reconocimiento de las ventajas de la visión integral para las actividades económicas que se realizan, teniendo en cuenta los referentes identitarios locales, la convivencia y la paz, la participación de las mayorías, una concepción a escala más humana, más llevadera en el tiempo, es decir, con elementos de cooperación, de economía social y solidaria, entre otros aspectos.

En el Cauca hay comunidades conscientes de un enfoque de bienestar local sostenible rural y de manera colectiva: En la zona rural de Popayán se reconocen estudiosos de agroecología ${ }^{14}$; en Patía ${ }^{15}$, Balboa ${ }^{16}$, Totoró ${ }^{17}$ y El Tambo ${ }^{18}$ se trabaja con

10 Se promueve la recuperación de Semillas locales, enseñanza de bailes y danzas tradicionales, memoria social,y lo han denominado "Enredijos culturales e historia ambiental".

11 Se incentiva en los estudiantes de la región, prácticas de Hidro-ecoturismo y deconstrucción de la historia ambiental del territorio

12 Con prácticas de lectura, poesía, el arte de vivir y la magia de la lectura y la palabra

13 Lo que también se ha llamado Ciencia, Tecnología e Innovación

14 En las veredas Clarete bajo y alto, municipio de Popayán

15 En el corregimiento de Galíndez

16 En el corregimiento de San Bernardo

17 En la vereda Florencia

18 En las veredas Chisquío, Las Botas, La Cuchilla, Cuatro Esquinas 
pedagogías alternativas; en Timbío ${ }^{19}$, El Tambo ${ }^{20}$, Popayán ${ }^{21}$ y Sotará22 ${ }^{2}$ e registran economías con solidaridad; en Puracé ${ }^{23}$, Popayán, La Sierra ${ }^{24}$, La Vega ${ }^{25}$, Patía, Bolívar $^{26}$, Inzá ${ }^{27}$ y San Sebastián ${ }^{28}$ se ocupan de fortalecer sus economías propias con trabajos interdisciplinarios. Todas estas experiencias dan cuenta de la preservación del ambiente, lideran proyectos participativos, fortalecen identidades locales, recuperan y valoran saberes otros, trabajan en seguridad, soberanía y autonomía alimentarias, con procesos productivos de comercio justo, agroindustriales orgánicos. En este sentido, el Comunitarismo se convierte en un criterio social, económico, cultural, ambiental y político que da luces para un enfoque "alternativo", diverso frente a las estrategias de un buen vivir, con acciones que permitan avanzar hacia una persona, una sociedad y un Estado con vocación, talante e identidad comunitaria.

\subsection{1 ¿Por qué las tensiones éticas y políticas entre Liberalismo y Comunitarismo?}

Estas tensiones éticas y políticas entre el Liberalismo y el Comunitarismo son centrales a la hora de concebir el sentido de lo comunitario (Maturana, 1992) por tres razones: Primera razón: mientras para el Liberalismo la solidaridad es un punto de llegada, para el Comunitarismo la solidaridad es un punto de partida. Para el Liberalismo todos los individuos tienen derecho a tomar iniciativas en cualquier tipo de empresa vital pero principalmente de tipo económico; en ese camino descubren que hay otros individuos que tienen intereses similares a los suyos, deciden libremente emprender una empresa organizativa y para darle solidez, deben recordar permanentemente que los otros son semejantes a ellos. Esto es lo que suele suceder, por ejemplo, entre los gremios de profesionales o los grandes y pequeños industriales o comerciantes. El Liberalismo llega a la solidaridad por medio del Contractualismo. Este es el caso de las cadenas productivas en Cauca, en las cuales es preciso organizarse para la producción, la transformación y para la comercialización con el fin de abastecer satisfactoriamente a los actores del eslabón siguiente, y así asegurar un mercado, asegurar la provisión de materia prima, mantener poder de negociación en ambas direcciones, controlar precios, obtener los recursos para sostener los créditos, hacer un manejo más eficiente de los factores de producción, hacer de la finca una empresa, sostener contrataciones formales e informales, formar parte de las dinámicas organizativas legales empresariales, para así acceder a otros beneficios económicos, políticos y sociales, entre otros aspectos.

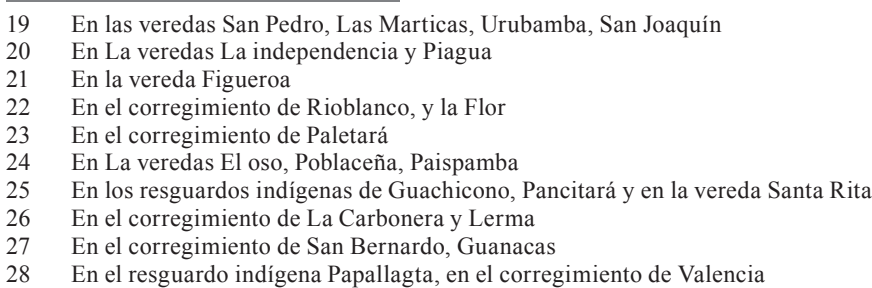


En cambio, para el Comunitarismo, los individuos desempeñan actividades trazadas por la Tradición, principalmente de tipo cultural y no requieren descubrir que los demás integrantes de la comunidad son culturalmente semejantes porque eso desde siempre ha hecho parte de su cosmovisión; la solidaridad comunitarista no requiere un acuerdo de voluntades para un contrato social sino la pertenencia a una tradición cultural. El Comunitarismo pone en evidencia que por fuera de la comunidad, el individuo no es autónomo sino anónimo. En este sentido, la solidaridad y el acto de solidarizarse, se asumen como un derecho que tiene toda persona u organización, que se realiza de manera autónoma y gozosa, satisfaciendo los intereses propios y los de los otros, llegando a ella por aprehensión y por seducción. Ejercer el derecho a solidarizarse en connotación comunitarista, es participar activamente en la gestión del bien común.

En La Carbonera y Lerma, municipio de Bolívar, en las veredas de La Cuchilla, Las Botas y Chisquío en El Tambo; en Rioblanco en Sotará; en Puracé, en La Vega; en las veredas de San Pedro, Las Marticas, San Joaquín, Urubamba, en Timbío, existen organizaciones que realizan prácticas productivas articuladas, con eslabonamientos claramente identificados que se resisten a enmarcarse dentro de la legalidad empresarial y la contratación formal pero en sus dinámicas resuelven necesidades humanas fundamentales de una mejor manera que si estuviesen dentro del esquema liberal. Que algunos comuneros decidan apartarse de su comunidad es un acto liberal o presionado por el Liberalismo, pero eso es otro asunto.

Segunda razón: en la tensión entre Liberalismo y Comunitarismo se ponen en evidencia los vínculos éticos, culturales y materiales que hay entre los individuos que conforman a una comunidad. En las comunidades urbanas en las que la tradición no es un vínculo fuerte -aunque en algunos casos haya trazas de ellos-, suelen surgir otros factores de reconocimiento y pertenencia, como las carencias y las precariedades. Estos vínculos materiales suelen ser muy fuertes en los momentos o períodos críticos, en los que no es difícil descubrir a los semejantes. En esos momentos, la solidaridad brota espontáneamente pero esa misma solidaridad tiende a diluirse cuando se supera la crisis y se va haciendo notoria la diferenciación individual mediante los mecanismos que propicia el Liberalismo a través del mercado (Escobar, 2005). La historia de las luchas sociales de tipo reivindicativo está llena de estos ejemplos.

Existen, no obstante, comunidades que sin una cosmovisión originaria, se reúnen alrededor de valores que alguien propone en forma relativamente espontánea, y que se tornan más fuertes en la medida en que abarquen más aspectos de la cotidianidad de los individuos y de sus imaginarios. Es el Caso de CORPOCIUR ${ }^{29}$ y de la Red de Agricultura Urbana Biológica de Popayán, ambas organizaciones comunitarias de base. La primera agrupa mujeres madres cabeza de familia que preparan almuerzos

29 Corporación Ciudad Red Gestor@s de vida de Popayán 
a muy bajo precio, al alcance de muchas familias de estratos cero, uno y dos; su propósito es fomentar la nutrición sana, saludable en las familias de bajos recursos. La segunda agrupa siete colegios oficiales de Popayán que le apuestan al mejoramiento de la seguridad y la soberanía alimentarias en los comedores escolares a través de las huertas, prácticas ecológicas, mecato saludable, autonomía alimentaria, entre otros aspectos. Esto, con el fin de construir, por una parte, prácticas de resistencia frente al hambre y la pobreza; por otra, elementos de historia ambiental con los niños, los jóvenes y los adultos de las comunas en donde se encuentran.

En esta misma dirección, se pueden incluir las inconformidades sociales y políticas que se convierten en movimientos sociales; el ecologismo de hoy es un ejemplo de ello, como desde hace varios años lo son el Sindicalismo, el Campesinismo o el Viviendismo.

En este contexto vale la pena llamar la atención sobre los denominados carismas que proliferaron entre las Comunidades católicas antes del Liberalismo y que una vez este les imputó el valor de cambio impuesto por el mercado a todas las actividades humanas (Oconnor, 1984, 1987), quedaron convertidos en comportamientos marginales o altruismos exóticos. Algunos comunitaristas contemporáneos como McIntyre (1976) ${ }^{30}$ señalan en esto un estancamiento e inclusive, un empobrecimiento de las posibilidades éticas para la humanidad.

En algunos casos -claro está-, los vínculos éticos comunitarios, más allá de convocar identidades pueden tornarse imponentes e intolerantes, como ha sucedido con algunas organizaciones religiosas o políticas y con algunos grupos étnicos o algunos Estados pero hay que recordar que el mismo riesgo se corre con el riesgo de corrupción y la soberbia de algunos individuos liberales. El Liberalismo ha encontrado un camino para acercarse al Comunitarismo por medio del mercado laboral. Al conformar grupos humanos dedicados a actividades productivas o de servicios que son afines, ha desarrollado a la Teoría Organizacional que hace énfasis en lo que se suele denominar misión, visión y sentido de pertenencia a la Organización Empresarial. De cierta manera, esta es una forma de tratar de restaurarle a la sociedad humana el empobrecimiento ético al que lo empuja constantemente el llamado "Capitalismo Salvaje", que otros rotulan como Neoliberalismo. En la perspectiva restauradora se inscriben todas las iniciativas que se promueven a través de la Cámara de Comercio del Cauca y el Sena, entre otras entidades.

Tercera razón: Comprender las tensiones entre el Liberalismo y el Comunitarismo ayuda a discernir entre el intervencionismo en todas sus modalidades y la

30 En su libro "Tras la virtud" (1976), Alasdair McIntyre hace una historia de la ética mediante una metodología narrativa, en la que da especial atención a la ética los hábitos, las virtudes, y el conocimiento de cómo alcanza el individuo una vida buena, en la que encuentren plenitud todos los aspectos de la vida humana. MacIntyre no elude hablar sobre temas particulares pero se acerca a ellos desde un contexto más amplio y menos legalista o normativista. Es éste un enfoque de la filosofía moral que, siguiendo a Aristóteles, aspira a demostrar cómo el juicio de un individuo nace del desarrollo del carácter. 
autonomía comunitaria. La tendencia liberal ha pasado por varios experimentos de intervención. El primero, desarrollado por los revolucionarios liberales y aunque parezca paradójico, por los socialistas, quienes empezaron acusando al Liberalismo precisamente de haber cercenado la libertad que tanto proclamaban. Según este experimento, el Revolucionario es un ser lúcido que tiene conciencia "en sí" y que debe integrarse a la masa que sufre, pero que no tiene conciencia de lo que le sucede.

Aunque hoy quedan rezagos de esta tendencia, el Liberalismo constató que el asunto es más complejo y que ninguna revolución se sostiene, si sus valores no son internalizados por la masa, y si no se tiene en cuenta el contexto en el que tendrá que sobrevivir la Revolución. Entonces se empezó a hablar, ya no de la revolución, sino del cambio social y del agente de cambio, quien a partir de entonces podría ser externo a la comunidad. No obstante, desde el punto de vista del agente de cambio, sigue siendo necesario promover entre los individuos de la comunidad, una visión crítica de la realidad para que, de esa manera, se propicien las transformaciones estructurales que sean necesarias.

Este enfoque llamado por algunos "promocional", se enfrentó al denominado enfoque "asistencialista", que aún hoy mitiga y camufla desórdenes estructurales. Se hace referencia en este caso a los programas que se ejecutan con recursos de Naciones Unidas, de la Unión Europea, los gobiernos nacionales, departamentales y municipales, como MIDAS, JUNTOS, los Laboratorios de Paz, ReSA, RICO, PLANTE, entre otros. Estos programas han llegado a las comunidades y cuando se han ido las han dejado en peores condiciones que las que encontraron a su llegada porque se generaron dependencias, y entonces se perdieron o disminuyeron las capacidades de autonomía para decidir sobre sus propios procesos de autoreconocimiento y para resolver sus propias necesidades. Los procesos asistencialistas sólo funcionaron mientras se ejecutaron los recursos para tal fin pero no generaron dinámicas locales para medianos o largos plazos. En Galíndez, municipio de Patía; en San Pedro, municipio de Timbío; en Guachicono, municipio de La Vega; en Rioblanco, municipio de Sotará; en Valencia, municipio de San Sebastián, en El Tambo, por ejemplo, realmente no se generaron dinámicas de fortalecimiento organizativo o productivo para darle continuidad a los procesos iniciados. Los ejercicios solidarios que se encuentran allí hoy en día son producto de procesos propios en los que no han mediado recursos económicos de parte de institución alguna.

Ahora bien, el Liberalismo mismo ha padecido luchas intestinas y hoy, por una parte, mantiene al asistencialismo principalmente desde el Estado (caso del programa Familias en Acción y de las Familias Guardabosques, entre otros) y por otra parte, pasa de la intervención con enfoque promocional a la intervención de tipo funcional. El enfoque funcional asume que la estructura social ya es cuasiperfecta y que dentro de ella, cada individuo debe aprender a desenvolverse libremente. Por esa razón, lo importante es la capacitación técnica, bien sea para resolver algunos problemas inmediatos, por ejemplo, por medio de una cierta manera de aplicar a la 
llamada “Investigación Acción”, o bien para salir a navegar en el mercado laboral. En Colombia el Servicio Nacional de Aprendizaje SENA, ha propuesto programas desde concepciones pedagógicas aparentemente interesantes pero que desembocan en la producción de más mano de obra calificada para un mercado laboral no siempre bien pagado, con lo cual la estrategia para llegar a la comunidad mediante la educación no formal ha distorsionado a la intención inicial y ha resultado funcional para un sistema salarial, que está perversamente basado en la tecnocracia.

Numerosas organizaciones gubernamentales y no gubernamentales que otrora practicaron el enfoque promocional, hoy practican un enfoque funcional-tecnocrático, dentro de un pragmatismo ${ }^{31}$ chato que no repara en la ausencia de equidad. Muchos de los cursos de educación no formal se ofrecen de manera masiva, sin consultarle a las comunidades si esto es lo que realmente necesitan para un buen o mejor vivir. La mayoría son cursos orientados a resolver sus problemas en el orden productivo $\mathrm{y}$, si se quiere, organizativo legal pero no tienen en cuenta las demás necesidades que no se resuelven con más ingresos ni con créditos que aumentan la dependencia. Es importante mencionar que aquel tipo de "Investigación - Acción" que se orientó a cuestionar e incluso a propiciar reales cambios estructurales, muy pronto fue estigmatizada y proscrita inclusive de la Academia. Los programas que se ofrecen a nivel universitario están cada vez más articulados a la propuesta liberal de sociedad individualista.

\subsubsection{Las lecciones de autonomía en los territorios continúan.}

Sin embargo, lo más importante es que muchas comunidades están reclamando el derecho a liderar sus propios procesos formativos e investigativos, desde su propia cosmovisión y desde el llamado "pensamiento propio", como es el caso del proyecto denominado "Universidad Autónoma Indígena Intercultural" 32 , donde se forja lo que allí denominan "un currículo propio". Con esa actitud, recientemente se ha dado el inicio de una Maestría en Gestión del Desarrollo con Identidad para el buen vivir. "Buen vivir" es una expresión con la cual algunas Comunidades Quechuas denominan a lo que se suele llamar "desarrollo". El buen vivir permite satisfacer

31 El pragmatismo como tendencia gnoseológica propende por vincular el aprendizaje a la vida productiva y ciudadana en busca del bien común. Sin embargo, en tiempos del neoliberalismo se suele despojar al pragmatismo de la búsqueda de la solidaridad y otros aspectos humanísticos para reducirlo a la búsqueda de rentabilidad, desde el supuesto según el cual la capacidad de consumo es la que garantiza la existencia del ciudadano. En términos éticos, el pragmatismo está relacionado con el utilitarismo. A diferencia de la propuesta moral de Rawls (1971), para el utilitarismo, propuesto por Stuart Mill a finales del siglo XIX, es más importante el resultado que el proceso. A diferencia de la ética Aristotélica para el utilitarismo de Stuart Mill la felicidad no consiste en la excelencia moral e intelectual sino en el placer de los sentidos. Así pues, para el utilitarismo lo importante es propiciar lo que el estado considere el máximo bienestar material al máximo número de personas, sin importar, por ejemplo, que se violente el derecho a opinar.

32 La UAIIN, Universidad Autónoma Indígena Intercultural, tiene sede en el Departamento del Cauca, hace parte de un proyecto llamado UII, Universidad Indígena Intercultural, que es impulsado por el Fondo para el Desarrollo de los Pueblos Indígenas de América Latina y el Caribe, a través del Consejo Regional Indígena del Cauca, CRIC. La Maestría en "Gestión del Desarrollo..." se implementa con docentes y estudiantes indígenas de varios países de América Latina. 
necesidades vitales en armonía con la comunidad y con la naturaleza. Es posible que el buen vivir también corresponda a lo que los comunitaristas contemporáneos, siguiendo al viejo Aristóteles, denominan felicidad.

En cuanto a las experiencias afrodescendientes, se puede pensar que la "Pedagogía de la Corridez" 33 en Galíndez, Patía, es una apuesta alternativa de formación, en la que se fortalece a la comunidad en muchos aspectos, y no se piensa sólo en una formación para el mercado y para la obtención de más ingresos en el futuro, sino en una formación integral para que los jóvenes permanezcan en sus territorios con una memoria social y ambiental. Esa es una formación para la vida, para un mejor vivir.

Una experiencia campesina similar se ve en Lerma y en La Carbonera ${ }^{34}$, comunidades del municipio de Bolívar en donde los valores humanos y la satisfacción de las necesidades humanas fundamentales se resuelven a través de una concepción diferente del territorio, una valoración por las semillas propias, la educación propia, la enseñanza campesino a campesino ${ }^{35}$, la medicina natural, la producción sin agroquímicos, el trabajo de las mujeres, los hombres, los mayores y los niños, los saberes locales, los procesos de producción y transformación en redes locales de mercadeo ya establecidas, valorando la cultura de la coca, construyendo procesos para una historia ambiental que hacen parte de sus cotidianidades.

En Inzá, la Asociación Campesina de Inzá Tierradentro ACIT fortalece procesos organizativos orientados hacia:

1. La identidad y la permanencia del campesinado en su territorio.

2. La lucha permanente por la tierra como un factor productivo al cual tienen derecho no sólo las minorías que la Ley cobija -en este caso, los indígenassino también las poblaciones campesinas, invisibilizadas actualmente en la constitución nacional.

3. Contra los éxodos en masa hacia la selva, los cuales generan aislamiento, soledad e inseguridad.

\subsection{3 ¿Por qué pensar en historia ambiental en los territorios locales?}

Dentro de la perspectiva liberal, hasta ahora el desarrollo se ha basado en la búsqueda de alternativas viables para resolver necesidades humanas desde la idea del derecho "natural" a explotar la naturaleza como algo "sobre -entendido". Por ese camino, a partir de la sociedad industrial se ha enfatizado en las necesidades del mercado más que en las de la población, con lo cual se ha hecho cada vez más manifiesta la subestimación de la tradición y la historia ambiental de los territorios,

33 Es la propuesta integral de la Profesora Lola, María Dolores Grueso, rectora de la IE Dos Ríos, en el corregimiento de Galíndez, Patía.

34 Es la experiencia del Comité de Integración del Macizo Colombiano CIMA al sur del departamento del Cauca.

35 Esta iniciativa corresponde a "Los agrosembradores", propuesta y desarrollada en el territorio caucano. 
es decir, del conjunto de interpretaciones acerca de los procesos bióticos, técnicosociales-culturales y abióticos, que más convienen a las comunidades para su subsistencia y para la creación y re-creación de cultura.

Lo que sucede es que la interacción de las comunidades humanas con la naturaleza ocurre durante la permanencia de ellas en el territorio y durante el trabajo, y en dicha interacción se establece una relación de doble vía: los grupos organizados adaptan y transforman a la naturaleza mientras esta los transforma a ellos. De esa manera, las comunidades alteran las condiciones climáticas y estas, a su vez, inciden sobre la cultura y la fisiología del cuerpo.

El problema es que esta situación se torna crítica dado que el ser humano trata de generar ritmos de crecimiento indeterminados e indefinidos, sin tener en cuenta que existen umbrales límites tanto para la naturaleza como para las comunidades. En este sentido, valioso será analizar diferentes nociones de territorio local y validar algunas estrategias económico-comunitaristas de la historia ambiental a la luz de las interacciones comunidad - naturaleza y de estos umbrales de crecimiento. Sobrepasar tales umbrales en los fragmentos del planeta habitados por el ser humano ha agudizado una relación conflictiva contra el resto de la naturaleza, en la que esta es usufructuada desmesurada e inequitativamente por la racionalidad humana, al punto que muchos de sus ciclos se han alterado irreversiblemente.

1.1.3.1. ¿Cómo se haría?: Se pueden estudiar varios casos de experiencias comunitarias y locales que buscan alternativas ambientalistas, desarrollistas y progresistas. Procedimentalmente se pueden reconstruir o establecer algunos casos de estudio desarrollados social y técnicamente por algunas comunidades. Entre los casos de estudio se encuentran la "Experiencia organizativa de los campesinos del macizo colombiano hacia la autonomía alimentaria" "36; el proyecto sobre la elaboración de un empaque activo biodegradable para plátano a partir de almidón modificado de yuca y capsaicina por extrusión soplado"37, la "experiencia organizativa de los caficultores en el municipio de El Tambo, Cauca"38; el proyecto "Experiencia formativa y organizativa de la pedagogía de la corridez en Galíndez, municipio de Patía, Cauca"39; el proyecto sobre la "Ordenación del recurso hídrico superficial en la parte baja de la subcuenca del Río Palo y apoyo al ordenamiento del recurso hídrico de la subcuenca Piedras" dos resguardos indígenas del municipio de la Vega, Cauca"41; el proyecto "Estrategia

36 En este se incluye el trabajo del comité de integración del Macizo Colombiano Fundecima en Lerma y La Carbonera, en Bolívar.

37 En este se incluye lo relacionado con los municipios productores y transformadores de yuca en Cauca y la Asociación de Municipios del Norte del Cauca Amunorca.

38 Con las comunidades de Asoproeco en Chisquío, Las Botas y La Cuchilla.

39 Con la profesora Lola de Galíndez.

40 Con Amunorca, Uafroc, con los ingenios azucareros y con la ACIN.

41 Con los resguardos de Guachicono y Pancitará. 
integral de monitoreo y evaluación de cambio climático en sistemas agrícolas y ecosistemas Altoandinos"42, y el proyecto "modelamiento climático, patrones de cambio y sus efectos en ecosistemas agrícolas altoandinos, identificando medidas de adaptación y mitigación para la planificación"43.

\section{A manera de conclusión}

Debido al creciente deterioro socioeconómico, organizativo, cultural, ambiental y al desgaste del sentido de lo público, apremia replantear las propuestas de bienestar que se están implementando desde la institucionalidad estatal, muchas veces proclamada como liberal. Es preciso fortalecer y replicar algunas experiencias que están aportando en la transformación y mejora de las condiciones de vida para los pueblos, hacia un buen vivir. Pretendiendo esbozar una opción que contribuya al análisis frente a la disyuntiva entre economía mercantilista y ecología preservacionista -mencionada al inicio de este artículo-, se puede decir que, debido a la subestimación de la historia ambiental de los territorios locales, hoy se asiste a una menor conciencia frente a los límites de los umbrales de crecimiento, lo cual trae efectos devastadores sobre la naturaleza, la sociedad en general y las comunidades (Martínez Alier, 1994). Por todo lo anterior, resulta interesante ahondar en el análisis de cómo lo económico/ comunitarista en la historia ambiental, ha configurado los territorios locales a la luz de los umbrales del crecimiento, y en medio de las tensiones entre liberalismo y comunitarismo.

No se trata solo de resolver el problema de pobreza caracterizada por los bajos ingresos, sino de resolver otras pobrezas que se viven en el departamento del Cauca, como la pobreza de sustento -alimentación y vivienda ineficientes-; la pobreza de protección -por tener un sistema de salud ineficiente y por la violencia asociada al narcotráfico y el conflicto armado-; la pobreza de afecto -por el autoritarismo, por las relaciones de explotación al medio ambiente, en donde el ser humano y la naturaleza están juntos-; la pobreza de entendimiento -por los perversos bajos niveles de educación para las mayorías-; la pobreza de participación -que se ve en la marginación de las mujeres, los niños, los mayores, las minorías-; la pobreza de identidad -porque de todas maneras se imponen valores extraños a las culturas locales o regionales, se obliga al desplazamiento forzado e incluso al exilio político y al desarraigo-. Con estas iniciativas alternativas de buen vivir se fortalecen procesos de valoración de su identidad local y regional en nutrición, bienestar y seguridad alimentaria; uso del tiempo libre, recreación y deporte; medicina tradicional, medicina blanca; convivencia, deberes y derechos humanos; estudio sociohistórico de las etnias, hidroecoturismo, oralidad y literatura, dignidad, danzas, teatro, música, economía propia, tecnologías locales, historia ambiental.

42 Con comunidades de Silvia, Sotará, La Vega, Totoró, Popayán y Puracé.

43 Con la participación de comunidades indígenas en Silvia, Puracé, Sotará y La Vega; y Campesinos en Popayán y Totoró. 
Iniciativas campesinas, indígenas y afrodescendientes, actualmente implementan estrategias para suplir sus necesidades humanas fundamentales y no sólo las de subsistencia: se reconocen propuestas alternativas que resuelven necesidades de ocio, recreación, libertad, identidad, protección, participación, entendimiento y afecto que tienen un gran acervo sociocultural, organizativo y ambiental no monetario, que le da a las comunidades elementos transformadores para mejorar su calidad de vida que, si se potencian, garantizarán una vida más digna para todos y todas en la región.

\section{Referencias}

Aristóteles. (1970). Ética a Nicómaco. Bogotá, Colombia: Gráficas Modernas.

García, N. (1990). Culturas hibridas. México: Grijalbo.

Escobar, A. (2005). Más allá del Tercer Mundo. Globalización y diferencia. Bogotá: ICANH, Universidad del Cauca.

Kant, E. (2000). Crítica a la razón práctica. Madrid: Alianza.

Martínez, J. (1994) De la economía ecológica a la ecología popular. Barcelona: Icaria Editorial S.A.

Maturana, H.; Varela, F. (1992). El árbol del conocimiento. Bases biológicas del entendimiento humano. Santiago de Chile: FCE. Edición revisada.

Max-Neet, M (1986). Desarrollo a escala humana. Santiago de Chile: Ediciones CEPAUR Fundación Dag Hammarskjold, Nordan Comunidad.

Mcintyre, A. (1976). Tras la virtud. Barcelona: Crítica.

Mill, S. (2002). Utilitarismo. Madrid: Alianza.

Quijano, O.(2010).Visiones y prácticas de diferencia Económico-culturalen Contextos de Multiplicidad, Capítulo 4. [Tesis Doctoral en Estudios Interculturales]. Quito; Universidad Simón Bolívar.

Rawls, J. (1971). Teoría de la justicia. Madrid: FCE.

UAIIN, Universidad Autónoma Indígena e Intercultural. (2009). Gestión del desarrollo con identidad para el buen vivir. Popayán: Autor. 